\title{
An overview of the workshop
}

\author{
Masatoshi KOBAYASHI ${ }^{\star}$ and Peter KEARNS \\ OECD Biosafety Team - Paris, 2 rue André Pascal, 75775 Paris, France
}

\section{INTRODUCTION}

The first intergovernmental discussions concerning the safety of uses of transgenic organisms occurred during the mid-1980s in the Organisation for Economic Cooperation and Development (OECD). The publication of OECD's Recombinant DNA Considerations (Blue Book) in 1986 was an important synthesis of the then proactive approaches to evaluating transgenic organisms by governments, scientists and other stakeholders. It was also the first intergovernmental document which addressed the environmental risk/safety of transgenic organisms. Many of the principles and concepts in the Blue Book have since been reflected in national laws, regulations and guidelines both in OECD countries and beyond.

2006 is the 20th anniversary of the publication of the Blue Book. With this in mind, the OECD has organized a number of activities or events during 2006 designed to take stock of OECD work related to safety in biotechnology and to identify future needs, especially with respect to non-member countries. The OECD workshop: Beyond the Blue Book - Framework for Risk/Safety Assessment of Transgenic Plants is one of the most important of these 2006 events and was organized with the following objectives in mind:

(1) to discuss the history and evolution of the conceptual framework for the evaluation of transgenic plant products in the environment and OECD's role in the development of that framework;

(2) to discuss the current contribution of OECD's Working Group on the Harmonization of Regulatory Oversight in Biotechnology to risk/safety assessment practice; and

(3) to discuss the future role of OECD with respect to current risk assessment issues and needs.

This workshop was held on 29th September 2006 in Jeju Island, Korea, in conjunction with the 9th International Symposium on Biosafety of Genetically Modified Organisms held by the International Society for Biosafety Research. It was hosted by the National Institute of Agricultural Biotechnology of Korea (NIAB) and sponsored

*Corresponding author: masatoshi.kobayashi@ oecd.org by the OECD's Cooperative Research Programme. The Chair of the Programme Committee for this Workshop was Ervin Balázs for Hungary. Approximately 110 stakeholders participated, including many who do not normally have the opportunity to attend meetings of OECD official bodies.

\section{OPENING}

The workshop began with the welcoming remarks by Gil-Bok Lee, the Director General of NIAB. He noted that OECD is one of the main intergovernmental bodies for international collaboration for ensuring the safety of products of modern biotechnology, which has produced some important past documents such as the Blue Book and more recently, the well-known Consensus Documents. Dr Lee stressed the importance of consensus documents to Korea. He noted that the drafting of two recently published documents on the biology of oyster mushroom and chili pepper, was led by Korean experts.

Opening remarks were also delivered by the Chair of the Working Group, Sally McCammon (USDA), who also chaired the workshop. She explained the background to the workshop, including an outline of the conceptual framework depicted within the Blue Book and subsequent publications developed at OECD. She made reference to some of the history of various OECD official bodies, which had undertaken this work, and described their functions and outputs. She noted that the outcomes of this workshop, including the presentations and discussion, would be considered by the Working Group on Harmonisation of Regulatory Oversight in Biotechnology (Working Group).

\section{PART I: THE FOUNDATION OF RISK/SAFETY ASSESSMENT}

The history and evolution of the OECD's risk/safety framework was explained by the first speaker, Hans Bergmans (Netherlands), a Vice-chair of OECD's Working Group. The Blue Book was outlined with an emphasis on the recommendation of the OECD's Council 
(a key element in the Blue Book), which clearly outlined the importance of "Case-by-Case" and "Stepwise" approaches to risk/safety analysis. These approaches were some of the earliest principles designed to address the safety of transgenic organisms.

"Safety Considerations for Biotechnology: Scale-up of Crop Plants" was published in 1993 to update and extend the work of the Blue Book. The concept of "familiarity" and the "points to consider" in scientific risk assessment (the characteristics of the recipient organism, the introduced trait, the environment into which the organism is to be introduced, the interaction between these, and the intended application) were among the main points. It was also stressed that these documents represented "snapshots" in time of an evolving safety framework that was (and can be) revised when new types of transgenic organisms are commercialized.

The contribution of OECD's work to the development of national and international risk/safety assessment framework was then addressed by Helmut Gaugitsch (Austria), a former Chair of OECD's Working Group. Amongst other things, he describes the relationship between OECD's work and that of the Cartagena Protocol on Biosafety, the International Plant Protection Convention (IPPC) and the activities of the Codex Alimentarius Commission.

He explained how the international visibility of OECD's work and broad participation of non-member economies and other intergovernmental organisations (IGOs) to OECD work has gradually increased over recent years. A good example was the reports submitted to the July 2000 G8 Summit of Heads of State and Government as well as the results of several follow-up conferences organised by the OECD. In addition, many of the recent outputs of the work had become increasingly influential including the plant biology and trait consensus documents as well as the database of commercial products. Co-operation with other IGOs has also had an important impact, for example, in the development of the Biosafety Clearing-House of the Cartagena Biosafety Protocol.

After these two presentations, there were a number of interventions from the floor. Many participants supported the work of OECD as valid and useful to many stakeholders concerned with the safety of transgenic plants. In particular, it was noted that OECD has played a key role in facilitating the formation of an international network of experts in risk/safety issues related to biotechnology.

\section{PART II: CURRENT PRACTICES FOR RISK/SAFETY ASSESSMENT}

This session began with a presentation by Philip Macdonald (Canada) on current activities in OECD related to risk/safety assessment. He emphasised the value of consensus and guidance documents that are the main outputs of the Working Group. He also described current projects, including work identifying "parameters for environmental risk/safety assessment" and as well as considerations on data related to "molecular characterisation" within the context of safety assessment.

Subsequently, there was a presentation on OECD activities by Bao-Rong Lu from the viewpoint of a university professor from China (a non-member economy). Amongst other things, he pointed out that the conceptual framework set up by OECD had contributed to China's regulatory framework and the influence of OECD documents could be seen in its domestic regulation. He mentioned that China today is a signatory to the Cartagena Protocol on Biosafety.

Another presentation from the perspective of a nonmember economy was given by Atanas Atanassov from Bulgaria. He reiterated the view that OECD's conceptual framework for environmental risk/safety assessment as well as the biology and trait Consensus Documents had been very useful when developing the domestic system in Bulgaria. He believed that it is important for OECD to continue its work on the risk/safety assessment, while continuing to focus on the involvement of non-member economies. In this context, he presented the work of the Black Sea Biotechnology Association. He encouraged OECD to support and assist in these kinds of regional organisations. Finally, some recommendations for future OECD activities were presented. Amongst other things, it included the continuing updating of the BioTrack Databases, the continuing involvement of nonmember economies in the production of Consensus Documents and co-operation with the Secretariat of the Convention on Biological Diversity.

Lisa Zannoni from the Business Industry Advisory Committee to the OECD (BIAC) presented a perspective on OECD activities from the point of view of product developers. She noted that the success of the work was due, to a large extent, to the active participation of delegates and other stakeholders involved in the work. She also mentioned potential future activities, notably, the importance of an environmental risk/safety assessment approach to the adventitious presence of transgenic crops, taking into account the work of the Codex Alimentarius Commission.

\section{PART III: POTENTIAL WAY FORWARD FOR RISK/SAFETY ASSESSMENT ISSUES}

This session was initiated by a presentation made by Sally McCammon, followed by panel presentations and discussion. In the initial presentation, the main points of two past initiatives of OECD which dealt with current 
and future issues in risk/safety assessment - the G8 Reports in 2000 and the results of an OECD Working Group Washington Workshop held in 2003 - were offered as a thought-starter for the subsequent panel presentation and discussion.

The panel consisted of scientists, regulators and representatives from industry. At the beginning of the discussion, each panellist briefly stated their own views, partly structured around a number of questions they had been asked in advance:

(1) Which concepts and instruments for the risk assessment of transgenic organisms, developed by OECD (e.g., familiarity, Consensus Documents) or elsewhere, did you apply in your setting? What has been most useful for your work, and why?

(2) What are the future needs for the field of environmental risk/safety assessment of transgenic organisms?

(3) What would be the most appropriate issues for the OECD to address among the future needs you raised?

(4) What kind of projects are of greatest priority for the OECD?

In the subsequent dialogue, there was general agreement, both from the panel and the audience, that many of the products of OECD's work over the years had been useful. From the mid-80s to the mid-90s, many of the principles described by some of the speakers (for example, the "stepwise" approach to safety assessment, "caseby-case" and "familiarity") had been useful, especially when OECD countries had been developing their approaches to safety assessment. This was also found to be true for a number of non-members economies.

As experience had been gained in risk/safety assessment, the Consensus Documents had become useful because they had stimulated discussion (and consensus) on the safety issues relevant to specific crop plants and traits. Taken as a whole, it was agreed that this work had fostered much international agreement on an approach to risk/safety assessment. Some participants expressed the view that the success of this work was due in part to the active contribution that delegations from countries made to the work as well as the active engagement of other stakeholders.

In terms of future work, there were a number of differing views from both panellists and the audience. Amongst other things, it was recognised that there still work to be done in refining assessment methods (problem formulation, hazard identification, endpoints, test protocols). Also, how to further apply the concept of familiarity. It was mentioned that there was a need to consider updating existing Consensus Documents. A number of participants mentioned the need to identify ways of improving the applicability of scientific research on biosafety to risk/safety assessment. This workshop was recognised as a good first step in achieving that.

It was also suggested that there should be an initiative to examine the possible development of agreed "test guidelines" for risk/safety assessment of transgenic organisms, and the application of Good Laboratory Practice. This suggestion stimulated some discussion from a broad range of perspectives. It was also noted that it might be timely for the Working Group to consider work on the environmental issues associated with "adventitious presence", while taking into account the work of the Codex Alimentarius Commission.

Amongst these various suggestions, there was no consensus on those issues that would be most appropriate to address in the future. At the same time, many participants noted that OECD's Working Group and the OECD Task Force for Novel Food and Feed (Task Force) had a heavy work load, but had successfully developed and used a mechanism in the past, by which delegations could identify priorities among existing and proposed projects. It was suggested the Working Group should organise such a priority-setting exercise in the near future. Many delegates also noted the successful way in which both the Working Group and the Task Force had engaged non-member economies in their work. This was recognized as a valuable trend which should be continued and strengthened in the future. Along similar lines, participants noted the value of the participation of other intergovernmental organisations in the various activities, as well as other stakeholders such as BIAC. 